\title{
Hurricane Preparation: A Q\&A Guide to Water and Food Safety and Quality 1
}

Amy Simonne and Ronald Schmidt ${ }^{2}$

\section{Section I: Water}

\section{How much drinking water should I have on hand for a family of four people?}

An active individual needs a minimum of two quarts of drinking water per day (FCS9195); thus, a family of four needs at least eight quarts (2 gallons) of drinking water per day.

\section{Is it okay to store water in plastic, capped,} water bottles that I refill?

If you reuse a disposable plastic bottle, do so with care and only use it for one month (Simonne, 2004). New plastic containers for water storage can be purchased in most housewares and sporting goods departments, and clean food-grade containers may be available for purchase at water vending machines. However, only use containers that are food grade and labeled for storage of food or beverages.

\section{How long can I keep the water in plastic bottles?}

If this is commercially packed water that it is packed according to the FDA Standards and stored properly as stated on the package, it could have an indefinite shelf life (FDA, 2002). For this reason, the FDA does not require an expiration date for bottled water. However, long-term storage of water may result in an off flavor.

1. This document is FCS8789, one of a series of the Family, Youth and Community Sciences Department, Florida Cooperative Extension Service, Institute of Food and Agricultural Sciences, University of Florida. Original publication date July 6, 2005. Visit the EDIS Web Site at http://edis.ifas.ufl.edu

2. Prepared by Amy H. Simonne, Assistant Professor, Family, Youth and Community Sciences, University of Florida and Ronald Schmidt, Professor, Food Science and Human Nutrition, University of Florida. Reviewed by Linda B. Bobroff, Professor, Family, Youth and Community Sciences, University of Florida; Glenda Warren, Associate Professor, Family, Youth and Community Sciences, University of Florida; Mary Peters, Extensions Agent IV, Broward County; Maisie Ross, Extension Agent III, Palm Beach County; Jackie Gibson, Extension Agent III, Miami-Dade County; Sandra Cannales, Extension Agent III, Miami-Dade County; Audrey Norman, Extension Agent I, Palm Beach County; Chris Procise, Extension Agent III, Martin County; Monica Dawkins, Extension Agent III, Miami-Dade County; Dianne Franzen, Extension Agent III, St. Lucie County; and Brenda Marty-Jimenez, Extension Agent II, Broward County.

This document was prepared in response to the questions posted by County Extension FCS faculty in Florida. Consumers in Florida counties frequently asked these questions during the 2004 hurricane season. Answers for each question have been prepared by using resources from UF/IFAS, federal agencies and other reputable sources including Talking About Disaster: Guide for Standard Messages (National Disaster Education Coalition, NDEC, 2004). This is an initial compilation of questions and answers which does not cover every single item related to emergency or hurricane situations. We welcome additional questions from those who use this document. They will be included, along with answers, in the next version of this publication.

The use of trade names in this publication is solely for the purpose of providing specific information. UF/IFAS does not guarantee or warranty the products named, and references to them in this publication does not signify our approval to the exclusion of other products of suitable composition. 
Because home packed water may not have as long a shelf life as commercially bottled water, it should be examined prior to use, especially after several months of storage. If the water becomes cloudy or has visible signs of algae growth or has an off flavor, the water should be discarded.

\section{Is it better to store water in glass or plastic containers?}

According to new guidelines you can store water in food grade plastic (NDEC, 2004). Glass containers are not recommended because they are heavy and they can break. Food-grade containers include those that previously held beverages, such as 2-liter soda bottles and other water, juice, or punch containers. Avoid plastic milk bottles. They may be difficult to clean sufficiently due to potential protein and/or fat residues. If not removed, these residues may allow bacteria to grow during storage.

\section{How do I purify water?}

You can purify water by boiling, distilling, or using a chemical treatment such as a dilute bleach solution.

Consult your local water authority for recommendations. Listen to a local radio station for announcements from appropriate authorities about the safety of drinking water. Follow their directions.

\section{Should I boil water for use in food preparation after a hurricane?}

If the safety of your water is in doubt, contact your local water authority to determine the potability (drinking water safety) of the water. If you are not sure of the safety of the water and cannot contact or reach the local authority, boil any water that will be used for food preparation, especially for foods that require no further cooking prior to consumption.

\section{How long should I boil water before drinking it if a "boil water" order is issued for my area?}

Our recommendation is to heat water to a rolling boil for 1 to 3 minutes. However, if this recommendation differs from that of the local Health Department, use their recommendation.
8. If I fill my bathtub with water, can I drink that water or should I only use it for personal hygiene and flushing the toilet?

Considering the normal uses of the bathtub, water stored in the bathtub is not potable (drinkable). One should store drinking water separately. If there is no other source of water and you must use water from the bathtub, it should be kept at a rolling boil for 1 to 3 minutes prior to drinking or using in food preparation.

\section{Section II: Refrigerated and Frozen Foods}

\author{
1. How long will the foods in the refrigerator \\ and freezer be safe after the power goes off? \\ - Refrigerator:
}

Refrigerated food should be safe as long as the power is out for no more than 4 hours. Keep the door closed as much as possible. Discard any perishable food such as meat, poultry, fish, eggs, and leftovers that have been above $40^{\circ} \mathrm{F}$ for 2 or more hours. Remember you can't rely on appearance or odor.

Foods that can be refrigerated/refrozen safely after being held above $40^{\circ} \mathrm{F}$ for more than 2 hours include: hard cheeses, butter or margarine, peanut butter, jelly, relish, taco sauce, mustard, ketchup, olives, pickles, opened vinegar-based dressings, bread, rolls, cakes without icing, muffins, quick breads, tortillas, and bagels.

\section{- Freezer:}

You will have to evaluate each item separately. If an appliance thermometer is kept in the freezer, read the temperature when the power comes back on. Normal freezer temperature should be below $0^{\circ} \mathrm{F}\left(-18^{\circ} \mathrm{C}\right)$. After a power outage, if the appliance thermometer stored in the freezer reads $40^{\circ} \mathrm{F}$ or below, the food is safe and may be refrozen. If a thermometer has not been kept in the freezer, check each package of food to determine the safety. If the food contains ice 
crystals or (is $40^{\circ} \mathrm{F}$ or below), it is safe to refreeze the food.

\section{How long can I store foods in an insulated cooler with ice?}

If the temperature is well maintained (at $40^{\circ} \mathrm{F}$ or below), the shelf life of food in the insulated cooler with ice is similar to when those foods are stored in the refrigerator. Discard any perishable food such as meat, poultry, fish, eggs, and leftovers that have been above $40^{\circ} \mathrm{F}$ for 2 hours.

\section{Which condiments and seasonings can be} safely kept without refrigeration and which should be discarded? Should I throw out jelly, mayonnaise, ketchup, mustard, and pickles?

In general, open vinegar, jelly, taco sauce, mustard, ketchup, olives, and pickles are safe at room temperature. However, you will have to evaluate each item separately. An unopened jar of commercial mayonnaise is safe without refrigeration, but if the jar is already open, discard the item.

\section{Which foods can be kept without refrigeration for at least a week?}

Any dried non-perishable foods such as unopened commercially canned foods, dried breakfast cereal, crackers, and cookies can be kept without refrigeration for at least a week.

5. Can I save the ice cream in my freezer if the power was out for 6 hours? The ice cream is only partially thawed. Is it safe to eat?

Partially thawed ice cream is safe to eat. But do not refreeze ice cream because the quality will be unacceptable.

\footnotetext{
6. Some of the food in my freezer had started to thaw or had thawed when the power came back on. Is the food safe?

If the appliance thermometer stored in the freezer reads $40{ }^{\circ} \mathrm{F}$ or below when the power comes on, the food is safe and may be refrozen. If a thermometer has not been kept in the freezer, check each package of food to determine the safety. Remember you can't rely on appearance or odor. If the food still contains
}

ice crystals (or is $40^{\circ} \mathrm{F}$ or below when checked by thermometer) it is safe to refreeze. (See answer to Question 1 for more information.)

\section{How long will a freezer keep food cold and safe during a power outage?}

If the freezer is closed, food may stay frozen at least a day or more depending on several factors including: the quantity of insulation, the size of the freezer, type of foods in the freezer, how the food is packed, and how full the freezer is. As a rule of thumb a full freezer stays cold longer than a half-full one, a freezer filled with meat stays cold longer than a freezer filled with baked goods, a well-insulated freezer keeps food frozen longer than one with little insulation, and the larger the freezer, the longer food stays frozen. Purchasing a freezer thermometer is recommended.

\section{May I refreeze foods that are partially or completely thawed?}

If the appliance thermometer stored in the freezer reads $40^{\circ} \mathrm{F}$ or below when the power comes back on, the food is safe and may be refrozen. Discard food items that have come into contact with raw meat juices. Partial thawing and refreezing may reduce the quality of some food, but the food will remain safe to eat. (See answer to Question 1 for more information).

\section{Section III: Use of Dry Ice}

\section{What is dry ice?}

Dry ice is the solid form of the gas carbon dioxide $\left(\mathrm{CO}_{2}\right)$. Dry ice has a much lower temperature than regular ice (frozen water). It is extremely cold $\left(-109.3^{\circ} \mathrm{F}\right.$ or $\left.-78.5^{\circ} \mathrm{C}\right)$. When using dry ice, handle it with care. DO NOT EAT DRY ICE.

\section{How do you properly and safely use dry ice?}

- Pick up dry ice as close as possible to when it is needed. Carry it in a well-insulated container such as an ice chest. If you transport dry ice in a car or van, make sure there is a fresh air supply. Use gloves, an oven mitt, or a folded towel when handling dry ice as it can burn the skin. 
- Dry ice can sublimate (change from a solid to a gas). Avoid breathing the gas, especially if you are in an airtight area, as it can cause suffocation. Dry ice is not stable, and in a closed container approximately 5 to $10 \%$ (5 to 10 pounds) is lost every 24 hours due to sublimation. This loss is accelerated in an open container or moist environment. Sickness and injury related to improper use of dry ice was reported during the 2004 hurricane season (MMWR [53:50: 1182-1183], 2004).

- Store dry ice in a thermally insulated container. The thicker the insulation, the slower it will sublimate or turn into carbon dioxide $\left(\mathrm{CO}_{2}\right)$ gas.

- Open the doors and allow adequate ventilation of places where dry ice was kept before entering. If you drive with dry ice in an enclosed vehicle, be sure to have proper ventilation. Keep proper air ventilation wherever dry ice is stored.

- If you notice that you feel faint or are breathing rapidly, you may be breathing too much of the $\mathrm{CO}_{2}$ gas. Leave the area immediately and get fresh air. $\mathrm{CO}_{2}$ is heavier than air and will accumulate in low spaces.

- You can dispose of small quantities of dry ice, away from the public, by leaving it outside or in a well-ventilated room at room temperature.

\section{Cautions:}

- Never store dry ice in a completely airtight container. The sublimation of dry ice to $\mathrm{CO}_{2}$ gas will cause any airtight container to expand and possibly rupture or burst.

- Never store dry ice in unventilated rooms, cellars, automobiles, or boat holds. The sublimated $\mathrm{CO}_{2}$ gas will sink to low areas and replace oxygenated air. This could cause suffocation if breathed exclusively.

- Never store dry ice in a running refrigerator freezer. The extremely cold temperature could cause your thermostat to turn off the freezer. Dry ice is useful for emergency cooling if your refrigerator breaks down.
- Never leave dry ice on a Formica ${ }^{\mathrm{TM}}$, plastic, or tiled countertop as the extreme cold could crack the countertop.

- Never leave dry ice unattended around children.

\section{Section IV: Food Safety After a Flood}

\section{Should I keep any food that gets wet from floodwater?}

Discard all food that comes in contact with floodwaters including canned goods. It is impossible to know if containers were damaged or if the seal was compromised.

\section{How should I clean dishes and pots that} have come in contact with floodwaters?

Thoroughly wash metal pans, ceramic dishes, and utensils with hot soapy water and sanitize by boiling them in clean water or by immersing them for 15 minutes in a solution of 1 teaspoon of chlorine bleach per quart of water.

\section{How do I disinfect cans and jars that have come in contact with floodwaters?}

Don't try to disinfect them! Discard all food (including canned foods) that came in contact with floodwaters. It is impossible to know if containers were damaged or the seal compromised.

\section{Which kitchen utensils should be discarded?}

Discard wooden cutting boards, plastic utensils, baby bottle nipples, and pacifiers. There is no way to safely clean them if they have come in contact with contaminated floodwaters.

\section{Section V: Emergency Supplies}

\section{1) Can you send me a list of a healthy "disaster" menu for three days? I want to still feed my family healthy foods during the hurricane and I don't want to buy foods loaded with salt, fat, and sugar.}

Food consumption is highly variable among different populations. Therefore, we recommend that consumers follow the current USDA Dietary 
Guidelines, and read food labels to make

healthful food choices that meet their

needs.

\section{Section VI: References}

FDA, 2002. Bottled Water Regulation and the FDA. http://vm.cfsan.fda.gov/ dms/botwatr.html

Simonne, 2004. To Reuse or Not to Reuse Plastic Bottles: Is There a Question?

http://fycs.ifas.ufl.edu/Newsletters/

research09.htm\#anchor5

USDA/FSIS 2004

http://www.fsis.usda.gov/Fact_Sheets/

keeping_food_Safe_during_an_emergency/index.asp

National Disaster Education Coalition, 2004.

Talking About Disaster: Guide for Standard

Messages,

http://www.disastereducation.org/guide.html 